\title{
Mate recognition and reproductive isolation in the sibling species Spodoptera littoralis and Spodoptera litura
}

\section{Ahmed M. Saveer ${ }^{1}$, Paul G. Becher ${ }^{1}$, Göran Birgersson ${ }^{1}$, Bill S. Hansson ${ }^{2}$, Peter Witzgall ${ }^{1}$ and Marie Bengtsson ${ }^{1}$}

1 Division of Chemical Ecology, Department of Plant Protection Biology, Swedish University of Agricultural Sciences, Sweden

2 Department of Evolutionary Neuroethology, Max Planck Institute for Chemical Ecology, Jena, Germany

Edited by:

Astrid T. Groot, University of

Amsterdam, Netherlands

\section{Reviewed by:}

Christine Merlin, Texas A\&M

University, USA

Maria Carolina Blassioli Moraes,

Embrapa Genetic Resources and

Biotechnology, Brazil

*Correspondence:

Ahmed M. Saveer, Department of

Plant Protection Biology, Box 102,

SE-230 53 Alnarp, Sweden

e-mail: ahmed.saveer@gmail.com
Mate recognition is crucial for reproductive isolation and for maintaining species integrity. Chemosensory-mediated sexual communication with pheromones is an essential component of mate recognition in moths. Confronted with sex pheromone stimuli released from conspecific and closely related heterospecific females, which partially overlap in chemical composition, male moths are under strong selection to recognize compatible mates. Here, we investigated the role of pheromone signals in premating communication in the sibling species Spodoptera littoralis and S. litura (Lepidoptera, Noctuidae). Further, we measured the reproductive consequence of conspecific vs. heterospecific matings. Both species use Z9,E11-14:Ac as the major pheromone compound, and the 11-component blend found in pheromone glands of $S$. littoralis comprises the compounds found in S. litura. Accordingly, S. littoralis and S. litura males readily responded to conspecific and heterospecific calling females in no-choice behavioral tests. In contrast, in a dual-choice test, $S$. littoralis males choose conspecific calling females, whereas $S$. litura males did not discriminate between conspecific and heterospecific females. In $S$. littoralis females, heterospecific matings had a negative fitness effect as compared to conspecific matings. Female longevity, egg-laying and hatching of larvae were significantly reduced by matings with heterospecific males. Reciprocal crossings, between $S$. litura females and $S$. littoralis males, were prevented by genital morphology, which is consistent with reduced heterospecific attraction of $S$. littoralis males in a dual-choice assay. On the other hand, matings between $S$. littoralis females and $S$. litura males, under a no-choice situation, show that interspecific matings occur in zones of geographical overlap and corroborate the idea that mate quality, in these closely related species, is a continuous and not a categorical trait.

Keywords: mate recognition, reproductive isolation, reproductive fitness, hybridization, gene flow, pheromone, Spodoptera

\section{INTRODUCTION}

In sexually reproducing animals, recognition of compatible mates is an essential component of reproductive success. Inaccuracies in mate recognition entail extended search time, energy expenditure, higher risk of predation and reduction in viable offspring. This exerts strong selection on mate recognition signals that maximize reproductive fitness and restricts gene flow between diverging lineages (Paterson, 1985; Shapiro, 2000; Mendelson and Shaw, 2012). Identifying mate recognition signals that ensure attraction of compatible mates and measuring the fitness consequences of those responses is essential for our understanding of the evolution of mate recognition systems and their role in phylogenetic divergence.

The chemical senses play a key role in mate recognition and premating isolation, and ultimately in speciation (Wyatt, 2003; Smadja and Butlin, 2009). Insects, and especially moths, use sex pheromones to attract and recognize potential mates. Male moths make long-distance flights to find compatible females emitting minute amounts of pheromone. Female-produced pheromones are often blends of two or more long-chain fatty acid derivatives. Within-species variations of pheromone blends are considered as prezygotic mating barriers that can lead to reproductive isolation and speciation (Schneider, 1992; Johansson and Jones, 2007; ElSayed, 2014). Such barriers however are not insurmountable and interbreeding of strains by male attraction to heterotype females have been studied, e.g., in fall armyworm Spodoptera frugiperda or European corn borer Ostrinia nubilalis (Pashley et al., 1992; Meagher and Nagoshi, 2004; Karpati et al., 2013; Unbehend et al., 2013). Closely related species typically use the same compounds in different proportions or partially overlapping blends, which may lead to heterotypic mate attraction (Ando et al., 2004; Groning and Hochkirch, 2008; Burdfield-Steel and Shuker, 2011; El-Sayed, 2014). The role of female sex pheromones in premating communication and mate choice is well established, but postmating fitness consequences as a result of premating decisions based on sex pheromones are understudied.

Here, we investigated olfactory-mediated mate recognition and reproductive isolation, and the fitness consequences of 
pre-mating decisions in two closely related noctuid moths, Egyptian cotton leafworm S. littoralis and oriental leafworm S. litura.

\section{METHODS \\ INSECTS}

Spodoptera littoralis (Lepidoptera, Noctuidae) was obtained from Dept. Entomology, Alexandria University (Egypt), S. litura from Dept. Applied Life Sciences, Kyoto University (Japan). The insects were reared on an semiartificial diet (Mani et al., 1978) at $23 \pm 1^{\circ} \mathrm{C}$ and $50-60 \%$ relative humidity $(\mathrm{RH})$, under a 16:8 L:D photoperiod. Adult insects were provided with water and 10\% sugar solution. All bioassays were done using 2- to 3-day-old moths.

\section{PHEROMONE GLAND EXTRACTION AND CHEMICAL ANALYSIS}

Pheromone glands of calling (pheromone-releasing) virgin female moths were dissected from the extruded ovipositors with a pair of fine forceps, starting 3-4h after onset of the scotophase. Moths were anesthetized under $\mathrm{CO}_{2}$ and decapitated before dissection. Glands in batches of 10 insects ( $S$. littoralis, $n=10$; S. litura, $n=5$; S. littoralis $\times S$. litura hybrid, $n=2$ ) were extracted during $2 \mathrm{~min}$ in $20 \mu \mathrm{l}$ redistilled heptane (LabScan). After the addition of $50 \mathrm{ng}$ of 13:Ac (Nu-ChekPrep, Inc.) as an internal standard, the gland extracts were analyzed on a coupled gas chromatograph-mass spectrometer (GC-MS; 6890 GC and 5975 MS, Agilent Technologies, Palo Alto, CA, USA), operated in the electron impact (EI) ionization mode at $70 \mathrm{eV}$. The GC was equipped with fused silica capillary columns $(30 \mathrm{~m} \times 0.25 \mathrm{~mm}, d f=0.25 \mu \mathrm{m})$, DB-Wax (J\&W Scientific, Folsom, CA, USA) or HP-5MS (Agilent Technologies), and helium was used as carrier gas at an average linear flow of $35 \mathrm{~cm} / \mathrm{s}$. Temperature was initially set to $80^{\circ} \mathrm{C}$ ( $5 \mathrm{~min}$ hold) and then programmed at $10^{\circ} \mathrm{C} / \mathrm{min}$ to $225^{\circ} \mathrm{C}(10 \mathrm{~min}$ hold $)$. Compounds were identified acording to mass spectra and retention times, including coinjection of synthetic standards, on two columns. Compounds were quantified by GC-MS. Purpose of this study is a comparative analysis of the same compounds produced in two species; all compounds are acetates of the chain length 14 and 16.

\section{WIND TUNNEL BIOASSAY}

Long-range male flight attraction to calling females was studied in a wind tunnel with a flight section of $180 \times 90 \times 60 \mathrm{~cm}$, illuminated at 2-3 lux, and the speed of incoming filtered air $\left(22-24^{\circ} \mathrm{C}, 50-60 \% \mathrm{RH}\right)$ was $30 \mathrm{~cm} / \mathrm{s}$ (see Witzgall et al., 2001; Saveer et al., 2012). Experiments were done 3-4 h after onset of the scotophase, when female pheromone-release reached a peak. Five calling females, each kept in an individual glass tube closed with gauze were placed on the platform at the upwind end of the tunnel. Virgin male moths were individually released from a glass tube on a platform ca. $150 \mathrm{~cm}$ downwind from the females and observed during up to $5 \mathrm{~min}$. Up to 20 males were tested on 1 day, $50 \mathrm{~S}$. littoralis males and $20 \mathrm{~S}$. litura males were flown in total. The following, sequential behavioral steps were recorded: activation, take-off, upwind flight and landing at a tube containing a female moth.

\section{DUAL-CHOICE WALKING BIOASSAY}

A dual-choice walking bioassay was conducted in the wind tunnel, under the same conditions as above. Males $(N=25$, for each species) were exposed to calling $S$. littoralis and $S$. litura females, which were kept individually in glass tubes covered with gauze. Tubes with placed $5 \mathrm{~cm}$ apart, in a side-by-side position at the upwind end of the wind tunnel. Individual virgin male moths were released from glass tubes ca. $75 \mathrm{~cm}$ downwind from the females. Males were observed during $5 \mathrm{~min}$ and were scored for arrival at the glass tubes containing females $(n=25)$. All males in the flight and walking bioasay were tested once.

\section{MATING AND EGG LAYING}

Conspecific and heterospecific pairs of unmated males and females were held individually in plastic containers $(\varnothing$ $10 \times 4 \mathrm{~cm}$ ). Observations of matings were made at $30-\mathrm{min}$ intervals throughout the 8 -h scotophase. All four mate combinations were tested, littoralis $\times$ littoralis, littoralis $\times$ litura, litura $\times$ litura, and litura $\times$ littoralis (female $\times$ male). For every individual pair ( $n=40$ to 50 ), mating success (number of successful matings), duration of mating and female longevity was recorded. Furthermore, we determined the number of egg batches laid and the viability of eggs.

\section{STATISTICAL ANALYSIS}

An exact binomial test was used to analyse the dual-choice walking assay of male moths. The difference in copulation duration between the two species was calculated using a non-parametric Kruskal-Wallis test, followed by Dunn's multiple comparisons between the groups. Mann Whitney test was performed to compare the differences in the oviposition and egg-hatching rate between con- and hetero-specific mating. The Kaplan-Meier method was employed to create survival curves (time until death) from the raw data and both a logrank (Mantel-Cox) test and the Gehan-Wilcoxon test were used to compare the survival curves. All statistical analyses were performed using GraphPad Prism.

\section{RESULTS}

\section{PHEROMONE BLEND COMPOSITION}

Chemical analysis of pheromone gland extracts of $S$. littoralis, $S$. litura, and hybrid females showed presence of eleven, four and seven compounds, respectively (Table 1). Four compounds, $(Z)$ 9-tetradecenyl acetate (Z9-14:Ac), (Z,E)-9,12-tetradecadienyl acetate (Z9,E12-14:Ac), (E,E)-10,12-tetradecadienyl acetate (E10,E12-14:Ac) and the major compound $(Z, E)-9,11$ tetradecadienyl acetate (Z9,E11-14:Ac) were consistently found in all female gland extracts. We also identified for the first time the three geometric isomers (EZ, EE, and $\mathrm{ZZ}$ ) of Z9,E11-14:Ac in S. littoralis. The isomers were not detected in S. litura female gland extracts, but E9,E11-14:Ac was found in gland extracts of hybrid females (Table 1).

\section{MALE FLIGHT ATTRACTION AND DUAL-CHOICE WALKING ASSAY TO FEMALE SEX PHEROMONE}

The upwind flight response of S. littoralis and S. litura males to conspecific and heterospecific calling females was not significantly different in a no-choice situation: $84 \%$ S. littoralis and 
Table 1 | Pheromone gland composition according to GC-MS analysis.

\begin{tabular}{|c|c|c|c|c|}
\hline & Compound & S. littoralis $( \pm S D)$ & S. litura $( \pm S D)$ & Hybrid $( \pm S D)$ \\
\hline 1 & $14: A c$ & $3(0.1)$ & - & - \\
\hline 2 & Z9-14:Ac & $29(2.2)$ & $23(0.12)$ & $63(0.4)$ \\
\hline 3 & $E 11-14: A c$ & $19(1.3)$ & - & - \\
\hline 4 & Z11-14:Ac & $12(0.8)$ & - & $6(0.1)$ \\
\hline 5 & Z11-16:Ac ${ }^{a}$ & $8(0.5)$ & - & $6(0.1)$ \\
\hline 6 & Z9,E11-14:Ac & $100(8.7)$ & $100(0.64)$ & $100(0.5)$ \\
\hline 7 & $Z 9, Z 11-14: A c^{a}$ & $2(0.3)$ & - & - \\
\hline 8 & $E 9, Z 11-14: A c^{a}$ & $6(0.3)$ & - & - \\
\hline 9 & $E 9, E 11-14: A c^{a}$ & $6(0.3)$ & - & $7(0.1)$ \\
\hline 10 & $Z 9, E 12-14: A c$ & $4(0.2)$ & $16(0.14)$ & $17(0.1)$ \\
\hline 11 & $E 10, E 12-14: A c$ & $22(1.2)$ & $23(0.12)$ & $29(0.1)$ \\
\hline
\end{tabular}

Glands in batches of 10 (Spodoptera littoralis, $n=10$; S. litura, $n=5$; S. littoralis $\times S$. litura hybrid, $n=2$ ). Numbers represent ratio of individual compounds in relation to major compound. Synthetic standards are gifts from David Hall, Greenwhich (11), M. Lettéré, Versailles (8, 9), Darwin W. Reed, Saskatoon (7), and were purchased from Bedoukian Research Inc. (5), Farchan Laboratories (4) and Pherobank (1-3, 6, 10).

${ }^{a}$ Compounds identified for the first time in S. littoralis.

S. litura males flew upwind and landed at female S. littoralis females, and $78 \% \mathrm{~S}$. littoralis males flew to S. litura females (Figure 1A). S. litura males failed to discriminate between conspecific and heterospecific calling females even in a choice test, 56 and $44 \%$ responded to $S$. littoralis and S. litura females, respectively (Figure 1B). In contrast, $80 \%$ S. littoralis males chose conspecific over S. litura females (Figure 1B), possibly because $S$. littoralis females produce a more complex pheromone blend than S. litura females (Table 1).

\section{CONSPECIFIC AND HETEROSPECIFIC MATINGS}

Heterospecific matings were successful only between $S$. littoralis females and S. litura males (Figure 2A). Although there was no difference in mating rate, compared with conspecific matings, the duration of hybrid matings was significantly shorter. In contrast, only very few $S$. litura females mated with $S$. littoralis males (Figure 2A), although $90 \%$ of S. littoralis males attempted matings (data not shown). The few $S$. litura $\times$ S. littoralis copulations were brief, lasting 2-3 min (Figure 2A).

\section{POST-MATING REPRODUCTIVE FITNESS}

Females of $S$. littoralis and $S$. litura laid significantly more eggs following conspecific matings, as compared with heterospecific matings, and significantly more eggs were fertilized during conspecific than heterospecific matings, as shown by egg hatch (Figure 2B). Although S. litura females laid fewer egg batches in comparison with $S$. littoralis, the hatching rate was very similar. Few eggs hatched following matings of $S$. littoralis females $\times S$. litura males, whereas no larvae hatched from eggs laid after attempted $S$. litura $\times$ S. littoralis matings (Figure 2B).

\section{SURVIVAL AFTER MATING}

We also measured the effect of mating on the lifespan of female moths (Figure 3). Unmated S. littoralis and S. litura females lived
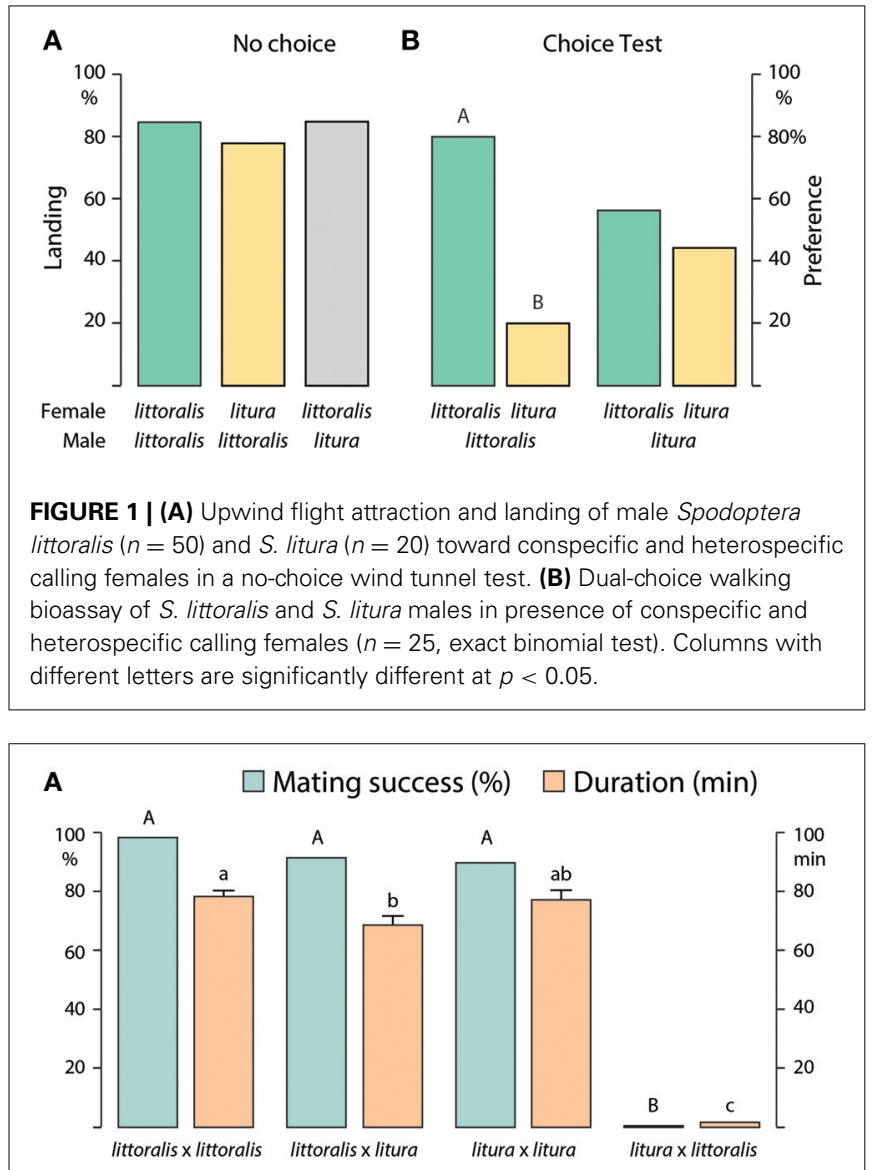

B

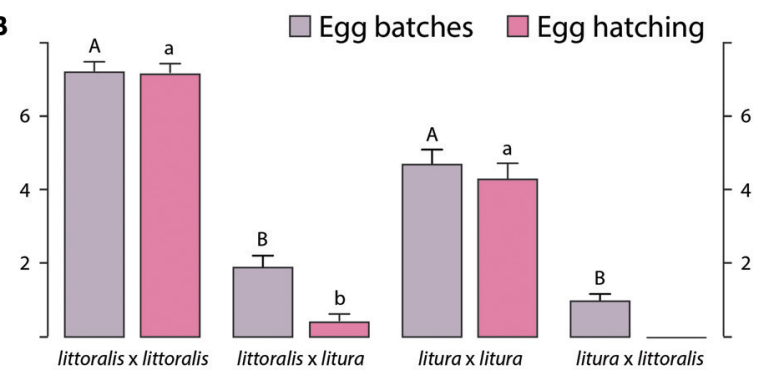

FIGURE 2 | (A) Successful conspecific and heterospecific Spodoptera littoralis and $S$. litura matings (\%; $n=40$ to 50 , Chi-square test) and duration ( $\mathrm{min} ; n=40$ to 50 , Kruskall-Wallis test). (B) Oviposition (mean number of egg batches per female) and larval hatching from egg batches, following conspecific and heterospecific matings (mean $\pm \mathrm{SE}, n=40$ to 50 , Mann-Whitney test). Matings shown as "female $\times$ male," columns with different letters are significantly different at $p<0.05$.

significantly longer than females mated with conspecific males. The median survival time of unmated $S$. littoralis and S. litura females was 14 and 11 days, while mated female lived 9 and 7 days, respectively. Strikingly, when female S. littoralis mated with $S$. litura males, the survival time of $S$. littoralis females significantly decreased even further, to a median of 7 days (Figure 3A).

\section{DISCUSSION}

Mate recognition and selection is basic for the maintenance of biological species. Specific mate recognition systems serve 


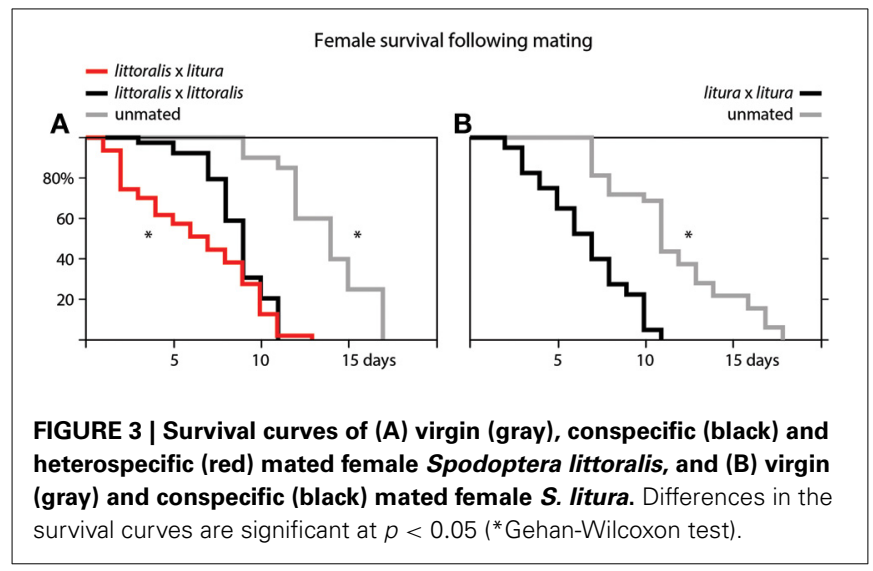

efficient conspecific mate finding first of all, while it is unclear whether avoidance of attraction to heterospecific signals is under strong selection (Paterson, 1985; Linn and Roelofs, 1995; Vrba, 1995). Mate quality and compatibility are not categorical, but continuous within species. Therefore, heterospecific matings are to be expected, especially in phylogenetically closely related species with adjacent, non-overlapping geographical distribution. S. littoralis is afrotropical and west-palearctic in distribution and overlaps with its east-palearctic and oriental sister species S. litura in Southern Iran and Pakistan (Kergoat et al., 2012). Our combined results suggest that hybrid matings occur in adjacent populations.

An overlap in sex pheromone composition results in interspecific attraction and hybrid matings, between $S$. littoralis females and $S$. litura males, albeit at a greatly reduced reproductive fitness (Figures 1-3). Male moths of both species showed strong attraction to heterospecific females in a no-choice situation. We assume this is based on the overlap in pheromone composition, namely the co-occurrence of the major $(Z 9, E 11-14: \mathrm{Ac})$ and the three minor components (Z9-14:Ac, Z9,E12-14:Ac, E10,E12-14:Ac). However, preferential attraction of male $S$. littoralis to conspecific females in a choice situation demonstrates the behavioral relevance of additional pheromone components, such as the isomers of the major component or additional compounds such as the two monoenens Z11-14:Ac and Z11-16:Ac (Table 1).

Interestingly, male $S$. litura failed to discriminate conspecific and heterospecific females in the choice assay and are also capable of producing hybrids when mating with $S$. littoralis females (Figures 1, 2). The temporal overlap in the calling behavior of S. littoralis and S. litura (data not shown) and the overlap in pheromone composition (Table 1) further counteracts reproductive isolation. In contrast, temporal partitioning in mating behavior is a mechanism that contributes to reproductive separation of strains in S. frugiperda (Pashley et al., 1992; Schoefl et al., 2011).

We found qualitative and quantitative differences in pheromone blend composition in the two species. We show for the first time the presence of all geometrical isomers of the main pheromone compound Z9,E11-14:Ac in the S. littoralis female gland (Table 1). Earlier studies on the pheromone composition of S. littoralis did not report these isomers (Nesbitt et al., 1973; Tamaki and Yushima, 1974; Martinez et al., 1990; Navarro et al., 1997; Munoz et al., 2008). In addition, we found Z11-16:Ac in S. littoralis. This monoene has not been reported before from S. littoralis, but has been found in other Spodoptera species (Bestmann et al., 1988; Cork et al., 1989; Mitchell and Tumlinson, 1994; Acín et al., 2010).

All sex pheromone components of S. litura were also found in S. littoralis, with only minor differences in relative amounts. S. littoralis and S. litura are the only two species of the genus Spodoptera that share same major and minor sex pheromone components (El-Sayed, 2014), indicating their close relatedness (Nagoshi et al., 2011; Kergoat et al., 2012). The hybrid female pheromone gland composition was more similar to S. littoralis, with three components (Z11-14:Ac, Z11-16:Ac and E9,E1114:Ac) in addition to the four compounds found in S. litura (Table 1), indicating maternal inheritance as in S. frugiperda (Groot et al., 2008).

The biosynthetic pathway of the pheromone components of S. littoralis has been studied in detail with labeling experiments by Munoz et al. (2008). Our findings of a number of new components in the female gland leads us to propose some additions to the published pathway, including a $E 9$-desaturase acting on both $E$ - and Z11-14:acyl giving rise to E9,E11-14:Ac and E9,Z1114:Ac respectively (Figure 4). Furthermore, we propose that the Z9-desaturase not only acts on E11-14:acyl as shown by Munoz et al. but also on Z11-14:acyl to produce Z9,Z11-14:Ac. Since all pheromone compounds produced by $S$. litura are found in $S$. littoralis, it is conceivable that the two species also share pheromone biosynthesis pathways (Figure 4).

Hybridization between laboratory populations of the two species is unidirectional. Only brief copulations were observed between $S$. litura females $\times S$. littoralis males, despite frequent copulation attempts by the males. Lack of matings may be due to differences in genital morphology (Venette et al., 2003), which has been widely documented in animals (Masly, 2012). S. littoralis and S. litura used in this study originate from Japan and Egypt, respectively, and studies of pheromone composition and genital morphology in zones of geographic overlap remains to be investigated.

Post-mating reproductive barriers were assessed through oviposition and hatching of larvae from egg batches. Although there was a difference in the number of egg batches laid by S. littoralis and S. litura following conspecific matings, fertilization rate was not different. In contrast, we measured a dramatic decrease in the number of egg batches laid and the number of fertilized eggs, when $S$. littoralis females mated with $S$. litura males (Figure 2B). The marked reduction in oviposition and hatching of interspecific crosses could be due to seminal proteins (Herndon and Wolfner, 1995) or poor fertilization and retention of unfertilized eggs (Gregory and Howard, 1993; Geyer and Palumbi, 2003).

We also show that mating greatly reduces the lifespan of female S. littoralis and S. litura moths (Figure 3). It been shown in fruit flies that male seminal proteins contribute to cost of mating in females and hence play a central role in the sexual conflict over optimal mating rates (Arnqvist and Nilsson, 2000; Avila et al., 2011; Mank et al., 2013). Strikingly, when female S. littoralis 


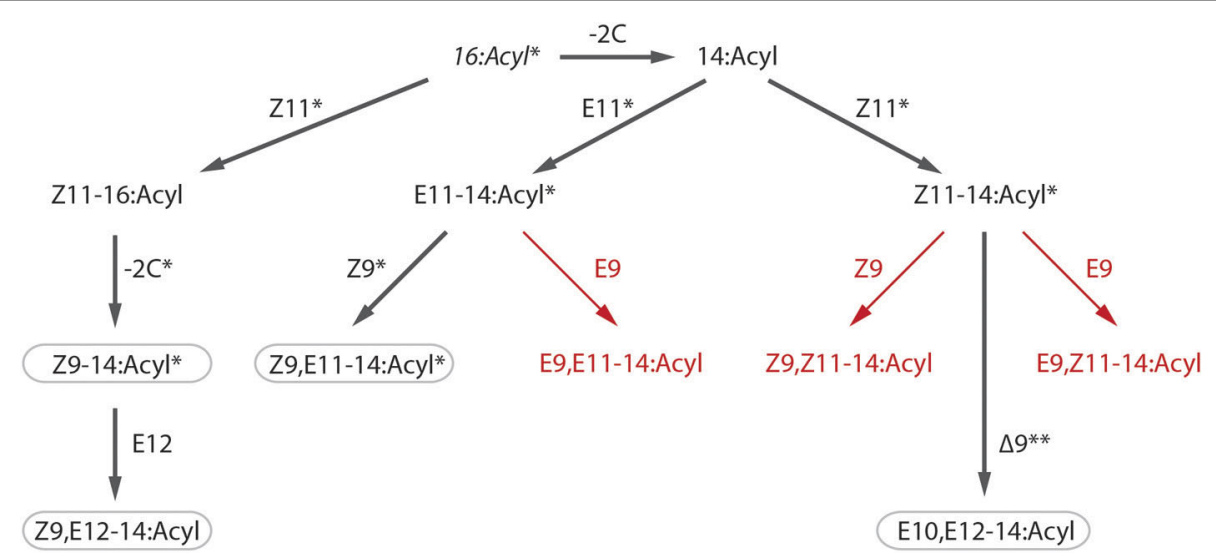

FIGURE 4 | Putative biosynthetic pathway of Spodoptera littoralis female sex pheromone. Steps confirmed by labeling experiments by Munoz et al. (2008) are indicated with asterisks $(*)$, including $\beta$-oxidation $(-2 C)$, desaturation $(Z 11, E 11, Z 9, E 9)$ and double bond migration $\left({ }^{* *}\right)$. Bold arrows show steps toward compounds found in both species, $S$. littoralis and $S$. litura (rounded rectangles), red arrows show proposed pathways for newly identified compounds in S. littoralis (see Table $\mathbf{1}$ ). mate with heterospecific males, their lifespan is even further reduced (Figure 3A). A more pronounced reduction in longevity after mating with a heterospecific partner suggests an incompatibility of heterospecific ejaculate and seminal proteins. Indeed, post-mating-prezygotic incompatibilities of the female reproductive tract are a main reason for reproductive isolation between Drosophila mojavensis and D. arizonae (Bono et al., 2011).

Our observations of heterospecific matings were made in the laboratory and it would be instructive to obtain field data to shape a more complete view of Spodoptera interspecies interactions. In natural habitats, associations with larval host plants add another degree of freedom to mate finding. Especially host plant volatile cues are known to synergistically interact with sex pheromones and to produce a much stronger and qualitatively different odor representation in the male antennal lobe, the olfactory center in the insect brain (Reddy and Guerrero, 2004; Trona et al., 2010, 2013; Chaffiol et al., 2012; Deisig et al., 2012). Plant odorants are known to affect pheromone perception also in Spodoptera (Binyameen et al., 2013; Zakir et al., 2013a,b).

Although Spodoptera species are considered to be rather polyphagous, individual insects or populations exhibit clear host plant preferences, for example the rice and corn strains of S. frugiperda (Pashley et al., 1992; Groot et al., 2010) and individual $S$. littoralis, as a result of larval experience (Thöming et al., 2013). It is crucial to study host plant associations in nature for a more complete understanding of Spodoptera mate recognition and reproductive isolation.

\section{CONCLUSION}

Recognition of compatible mates is an essential part of reproductive fitness. One of the conundra for mate selection is to which extent compatible mates are recognized before mating and how such mating decisions ultimately affect reproductive fitness. Our study suggests that pheromone communication in Spodoptera moths is a primary indicator of mate compatibility. Reproductive interference due to overlap in mate recognition signals, leading to heterospecific mating, is likely to occur between the sibling
Spodoptera species, although heterospecific matings infer a substantial fitness cost. Our findings show that mate compatibility is a continuous and not a categorical trait, from pre-mating decision to post-mating events that finally determine reproductive success.

\section{ACKNOWLEDGMENTS}

We thank Prof. Esmat Hegazi (Alexandria, Egypt) and Prof. Naoki Mori (Kyoto, Japan) for providing insects and Kate Umbers (Wollongong, Australia) for helpful comments on the first manuscript version. This study was supported by the Linnaeus environment "Insect Chemical Ecology, Ethology and Evolution" IC-E3 (The Swedish Research Council Formas, SLU) and a Formas grant for young researchers (Paul G. Becher).

\section{REFERENCES}

Acín, P., Rosell, G., Guerrero, A., and Quero, C. (2010). Sex pheromone of the Spanish population of the beet armyworm Spodoptera exigua. J. Chem. Ecol. 36, 778-786. doi: 10.1007/s10886-010-9817-z

Ando, T., Inomata, S.-I., and Yamamoto, M. (2004). "Lepidopteran sex pheromones," in The Chemistry of Pheromones and Other Semiochemicals, ed S. Schulz (Heidelberg: Springer Berlin), 51-96.

Arnqvist, G., and Nilsson, T. (2000). The evolution of polyandry: multiple mating and female fitness in insects. Anim. Behav. 60, 145-164. doi: 10.1006/anbe.2000.1446

Avila, F. W., Sirot, L. K., LaFlamme, B. A., Rubinstein, C. D., and Wolfner, M. F. (2011). Insect seminal fluid proteins: identification and function. Annu. Rev. Entomol. 56, 21-40. doi: 10.1146/annurev-ento-120709-144823

Bestmann, H. J., Attygalle, A. B., Schwarz, J., Vostrowsky, O., and Knauf, W. (1988). Identification of sex pheromone components of Spodoptera sunia Guenée (Lepidoptera: Noctuidae). J. Chem. Ecol. 14, 683-690. doi: 10.1007/BF010 13915

Binyameen, M., Hussain, A., Yousefi, F., Birgersson, G., and Schlyter, F. (2013). Modulation of reproductive behaviors by non-host volatiles in the polyphagous egyptian cotton leafworm, Spodoptera littoralis. J. Chem. Ecol. 39, 1273-1283. doi: 10.1007/s10886-013-0354-4

Bono, J. M., Matzkin, L. M., Kelleher, E. S., and Markow, T. A. (2011). Postmating transcriptional changes in reproductive tracts of con- and heterospecifically mated Drosophila mojavensis females. Proc. Natl. Acad. Sci. U.S.A. 108, 7878-7883. doi: 10.1073/pnas.1100388108

Burdfield-Steel, E. R., and Shuker, D. M. (2011). Reproductive interference. Curr. Biol. 21, R450-R451. doi: 10.1016/j.cub.2011.03.063 
Chaffiol, A., Kropf, J., Barrozo, R., Gadenne, C., Rospar, J. P., and Anton, S. (2012). Plant odour stimuli reshape pheromonal representation in neurons of the antennal lobe macroglomerular complex of a male moth. J. Exp. Biol. 215, 1670-1680. doi: 10.1242/jeb.066662

Cork, A., Murlis, J., and Megenasa, T. (1989). Identification and field testing of additional components of female sex pheromone of African armyworm, Spodoptera exempta (Lepidoptera: Noctuidae). J. Chem. Ecol. 15, 1349-1364. doi: 10.1007/BF01014835

Deisig, N., Kropf, J., Vitecek, S., Pevergne, D., Rouyar, A., Sandoz, J. C., et al. (2012). Differential interactions of sex pheromone and plant odour in the olfactory pathway of a male moth. PLOS ONE 7:e33159. doi: 10.1371/journal.pone.0033159

El-Sayed, A. M. (2014). The Pherobase: Database of Pheromones and Semiochemicals. Available online at: www.pherobase.com

Geyer, L. B., and Palumbi, S. R. (2003). Reproductive character displacement and the genetics of gamete recognition in tropical sea urchins. Evolution 57, 1049-1060. doi: 10.1111/j.0014-3820.2003.tb00315.x

Gregory, P. G., and Howard, D. J. (1993). Laboratory hybridization studies of Allonemobius fasciatus and A. socius (Orthoptera, Gryllidae). Ann. Entomol. Soc. Am. 86, 694-701.

Groning, J., and Hochkirch, A. (2008). Reproductive interference between animal species. Q. Rev. Biol. 83, 257-282. doi: 10.1086/590510

Groot, A., Marr, M., Schofl, G., Lorenz, S., Svatos, A., and Heckel, D. (2008). Host strain specific sex pheromone variation in Spodoptera frugiperda. Front. Zool. 5:20. doi: 10.1186/1742-9994-5-20

Groot, A. T., Marr, M., Heckel, D. G., and Schofl, G. (2010). The roles and interactions of reproductive isolation mechanisms in fall armyworm (Lepidoptera: Noctuidae) host strains. Ecol. Entomol. 35, 105-118. doi: 10.1111/j.13652311.2009.01138.x

Herndon, L. A., and Wolfner, M. F. (1995). A Drosophila seminal fluid protein, Acp26Aa, stimulates egg laying in females for 1 day after mating. Proc. Natl. Acad. Sci. U.S.A. 92, 10114-10118. doi: 10.1073/pnas.92.22. 10114

Johansson, B. G., and Jones, T. M. (2007). The role of chemical communication in mate choice. Biol. Rev. 82, 265-289. doi: 10.1111/j.1469-185X.2007. 00009.x

Karpati, Z., Tasin, M., Carde, R. T., and Dekker, T. (2013). Early quality assessment lessens pheromone specificity in a moth. Proc. Natl. Acad. Sci. U.S.A. 110 7377-7382. doi: 10.1073/pnas.1216145110

Kergoat, G. J., Prowell, D. P., Le Ru, B. P., Mitchell, A., Dumas, P., Clamens, A. L., et al. (2012). Disentangling dispersal, vicariance and adaptive radiation patterns: a case study using armyworms in the pest genus Spodoptera (Lepidoptera: Noctuidae). Mol. Phylogen. Evol. 65, 855-870. doi: 10.1016/j.ympev.2012. 08.006

Linn, C. E., and Roelofs, W. L. (1995). "Pheromone communication in moths and its role in the speciation process," in Speciation and the Recognition Concept: Theory and Application, eds D. M. Lambert and H. Spencer (Baltimore, MD: John Hopkins University Press), 263-300.

Mani, E., Riggenbach, W., and Mendik, M. (1978). Zucht des Apfelwicklers (Laspeyresia pomonella L.) auf künstlichem Nährboden, 1968-1978. Mitt. Schweiz. Entomol. Ges. 51, 315-326.

Mank, J. E., Wedell, N., and Hosken, D. J. (2013). Polyandry and sex-specific gene expression. Philos. Trans. R. Soc. Lond. B Biol. Sci. 368, 20120047. doi: 10.1098/rstb.2012.0047

Martinez, T., Fabrias, G., and Camps, F. (1990). Sex pheromone biosynthetic pathway in Spodoptera littoralis and its activation by a neurohormone. J. Biol. Chem. 265, 1381-1387.

Masly, J. P. (2012). 170 Years of "lock-and-key": genital morphology and reproductive isolation. Int. J. Evol. Biol. 2012:247352. doi: 10.1155/2012/ 247352

Meagher, R. L., and Nagoshi, R. N. (2004). Population dynamics and occurrence of Spodoptera frugiperda host strains in southern Florida. Ecol. Entomol. 29, 614-620. doi: 10.1111/j.0307-6946.2004.00629.x

Mendelson, T. C., and Shaw, K. L. (2012). The (mis)concept of species recognition. Trends. Ecol. Evol. 27, 421-427. doi: 10.1016/j.tree.2012.04.001

Mitchell, E. R., and Tumlinson, J. H. (1994). Response of Spodoptera exigua and S. eridania (Lepidoptera: Noctuidae) males to synthetic pheromone and S. exigua females. Florida Entomol. 77, 237-247. doi: 10.2307/34 95509
Munoz, L., Rosell, G., Quero, C., and Guerrero, A. (2008). Biosynthetic pathways of the pheromone of the Egyptian armyworm Spodoptera littoralis. Physiol. Entomol. 33, 275-290. doi: 10.1111/j.1365-3032.2008.00645.x

Nagoshi, R. N., Brambila, J., and Meagher, R. L. (2011). Use of DNA barcodes to identify invasive armyworm Spodoptera species in Florida. J. Insect Sci. 11, 1-11. doi: 10.1673/031.011.15401

Navarro, I., Mas, E., Fabrias, G., and Camps, F. (1997). Identification and biosynthesis of (E,E)-10,12-tetradecadienyl acetate in Spodoptera littoralis female sex pheromone gland. Bioorg. Med. Chem. 5, 1267-1274. doi: 10.1016/S09680896(97)00072-2

Nesbitt, B. F., Beevor, P. S., Cole, R. A., Lester, R., and Poppi, R. G. (1973). Sex pheromones of two noctuid moths. Nat. New Biol. 224, 208-209. doi: 10.1038/newbio244208a0

Pashley, D. P., Hammond, A. M., and Hardy, T. N. (1992). Reproductive isolating mechanisms in fall armyworm host strains (Lepidoptera: Noctuidae). Ann. Entomol. Soc. Am. 85, 400-405.

Paterson, H. E. H. (1985). "The recognition concept of species," in Species and Speciation, ed E. S. Vrba (Pretoria: Transvaal Museum Monograph No. 4), 21-29.

Reddy, G. V. P., and Guerrero, A. (2004). Interactions of insect pheromones and plant semiochemicals. Trends Plant Sci. 9, 253-261. doi: 10.1016/j.tplants.2004.03.009

Saveer, A. M., Kromann, S. H., Birgersson, G., Bengtsson, M., Lindblom, T., Balkenius, A., et al. (2012). Floral to green: mating switches moth olfactory coding and preference. Proc. Biol. Soc. 279, 2314-2322. doi: 10.1098/rspb.20 11.2710

Schneider, D. (1992). 100 years of pheromone research. An essay on Lepidoptera. Naturwissenschaften 79, 241-250. doi: 10.1007/BF01175388

Schoefl, G., Dill, A., Heckel, D. G., and Groot, A. T. (2011). Allochronic separation versus mate choice: nonrandom patterns of mating between fall armyworm host strains. Am. Nat. 177:470-485. doi: 10.1086/658904

Shapiro, L. H. (2000). Reproductive costs to heterospecific mating between two hybridizing katydids (Orthoptera: Tettigoniidae). Ann. Entomol. Soc. Am. 93, 440-446. doi: 10.1603/0013-8746(2000)093[0440:RCTHMB] 2.0.CO;2

Smadja, C., and Butlin, R. K. (2009). On the scent of speciation: the chemosensory system and its role in premating isolation. Heredity 102, 77-97. doi: 10.1038/hdy.2008.55

Tamaki, Y., and Yushima, T. (1974). Sex pheromone of the cotton leafworm Spodoptera littoralis. J. Insect Physiol. 20, 1005-1014. doi: 10.1016/00221910(74)90142-5

Thöming, G., Larsson, M. C., Hansson, B. S., and Anderson, P. (2013). Comparison of plant preference hierarchies of male and female moths and the impact of larval rearing hosts. Ecology 94, 1744-1752. doi: 10.1890/12-0907.1

Trona, F., Anfora, G., Balkenius, A., Bengtsson, M., Tasin, M., Knight, A., et al. (2013). Neural coding merges sex and habitat chemosensory signals in an insect herbivore. Proc. R. Soc. B 280:20130267. doi: 10.1098/rspb.20 13.0267

Trona, F., Anfora, G., Bengtsson, M., Witzgall, P., and Ignell, R. (2010). Coding and interaction of sex pheromone and plant volatile signals in the antennal lobe of the codling moth Cydia pomonella. J. Exp. Biol. 213, 4291-4303 doi: 10.1242/jeb.047365

Unbehend, M., Hänniger, S., Meagher, R., Heckel, D., and Groot, A. (2013). Pheromonal divergence between two strains of Spodoptera frugiperda. J. Chem. Ecol. 39, 364-376. doi: 10.1007/s10886-013-0263-6

Venette, R. C., Davis, E. E., Zaspel, J., Heisler, H., and Larson, M. (2003). Mini Risk Assessment: Egyptian Cotton Leafworm, Spodoptera Littoralis Boisduval (Lepidoptera: Noctuidae). Available online at: http://www.aphis.usda.gov/plant_health/plant_pest_info/pest_detection//down loads/pra/slittoralispra.pdf

Vrba, E. S. (1995). "Species as habitat-specific, complex systems," in Speciation and the Recognition Concept: Theory and Application, eds D. M. Lambert and H. Spencer (Baltimore, MD: John Hopkins University Press), 3-44.

Witzgall, P., Bengtsson, M., Rauscher, S., Liblikas, I., Bäckman, A.-C., Coracini, M., et al. (2001). Identification of further sex pheromone synergists in the codling moth, Cydia pomonella. Entomol. Exp. Appl. 101, 131-141. doi: 10.1046/j.15707458.2001.00898.x

Wyatt, T. D. (2003). Pheromones and Animal Behaviour: Communication by Smell and Taste. Cambridge: Cambridge University Press. 
Zakir, A., Bengtsson, M., Sadek, M. M., Hansson, B. S., Witzgall, P., and Anderson, P. (2013a). Specific response to herbivore-induced de novo synthesized plant volatiles provides reliable information for host plant selection in a moth. J. Exp. Biol. 216, 3257-3263. doi: 10.1242/jeb.083188

Zakir, A., Sadek, M. M., Bengtsson, M., Hansson, B. S., Witzgall, P., and Anderson, P. (2013b). Herbivore-induced plant volatiles provide associational resistance against an ovipositing herbivore. J. Ecol. 101, 410-417. doi: 10.1111/13652745.12041

Conflict of Interest Statement: The authors declare that the research was conducted in the absence of any commercial or financial relationships that could be construed as a potential conflict of interest.
Received: 26 March 2014; accepted: 01 May 2014; published online: 19 May 2014. Citation: Saveer AM, Becher PG, Birgersson G, Hansson BS, Witzgall P and Bengtsson $M$ (2014) Mate recognition and reproductive isolation in the sibling species Spodoptera littoralis and Spodoptera litura. Front. Ecol. Evol. 2:18. doi: 10.3389/fevo.2014.00018

This article was submitted to Chemical Ecology, a section of the journal Frontiers in Ecology and Evolution.

Copyright (C) 2014 Saveer, Becher, Birgersson, Hansson, Witzgall and Bengtsson. This is an open-access article distributed under the terms of the Creative Commons Attribution License (CC BY). The use, distribution or reproduction in other forums is permitted, provided the original author(s) or licensor are credited and that the original publication in this journal is cited, in accordance with accepted academic practice. No use, distribution or reproduction is permitted which does not comply with these terms. 